\title{
The Relative Influence of Proximity to Fast Road Infrastructure, Accessibility, and Deprivation on Crime
}

\author{
Margaret O’Mahony (D) \\ Trinity Centre for Transport Research, Department of Civil, Structural \& Environmental Engineering, Trinity College Dublin, \\ Dublin 2, Ireland \\ Correspondence should be addressed to Margaret O’Mahony; margaret.omahony@tcd.ie
}

Received 31 October 2017; Revised 28 February 2018; Accepted 15 March 2018; Published 23 April 2018

Academic Editor: Juan C. Cano

Copyright (c) 2018 Margaret O’Mahony. This is an open access article distributed under the Creative Commons Attribution License, which permits unrestricted use, distribution, and reproduction in any medium, provided the original work is properly cited.

Irish rural areas saw an increase in the number of burglaries in the period following the completion of a network of high speed motorway interurban routes. To test the hypothesis that the new fast infrastructure was providing quick exits by urban based criminal gangs, Irish crime statistics along with census data were combined in a logistic regression analysis to assess the relative influence of accessibility, deprivation, population, and proximity to fast road infrastructure on the number of burglaries in areas. It was found that accessibility had a higher influence on crime than area deprivation and that proximity to fast road infrastructure was not significant.

\section{Introduction}

In relation to the association between socioeconomic status and criminal offending, the literature suggests that poverty has an effect on serious crime [1]. Relative deprivation is more important than absolute poverty [2] and others suggest that the educational level of parents is key [1]. Differences in spatial distribution of crime have been found [3]; for instance, crime is typically higher in urban areas [4] and in neighborhoods with high population density [5].

Drawve and Barnum [6] noted that crime is influenced by physical place features such as alcohol outlets, restaurants, and public transportation stops. They developed a more discerning method of analysis where different police divisions in a single city were viewed as their own environmental contexts to produce localized spatial risk assessments. Other work noted that it is the clustering of disadvantaged neighborhoods in close proximity that is particularly problematic [7].

Deprivation indices are practical measures that can be used to identify areas characterized by socioeconomic marginalization [8]. Stucky et al. [9] found that, consistent with previous research, lower levels of income were associated with higher violent and property crime counts and that local and nearby income inequality affects crime. When developing deprivation indices for Ireland, Haase and Pratschke [10] used scores that can enable comparisons to be made over time. This approach was first applied in an analysis of data from the 1991, 1996, and 2002 census [10] and is used in the current Pobal HP Deprivation Index for Small Areas [11]. The index focuses on three dimensions: demographic profile, social class composition, and the labour market situation. The index has gained recognition for being the first censusbased index that has enabled comparability of a multivariate measure of deprivation over successive census periods. The work presented here uses the HP Deprivation Index as an indication of the socioeconomic characteristics of an area as a means of capturing the potential influence that may have on crime in the area.

In relation to the connection between transport and crime, others [12-14] have focused on the links between public transport and crime and in particular the impact that crime has on public transport use and personal safety while using transport facilities. Little research has been done on the influence of proximity to fast road networks on crime to date and the research presented here attempts to fill that gap.

Ireland is an island with a population of 4.7 million situated on the west of Europe. Its capital city is Dublin, on the east coast, and four other cities, Cork, Galway, Limerick, and Waterford, are key urban areas in a predominantly rural country. Faced with the challenges that the provision of 
TABle 1: Proximity to service centre scoring system [15].

\begin{tabular}{|c|c|c|c|c|c|c|}
\hline \multirow{2}{*}{ Population } & \multirow{2}{*}{ Level } & \multicolumn{5}{|c|}{ Time from ED } \\
\hline & & $<10$ mins & 10-20 mins & 20-30 mins & $30-60$ mins & $>60$ mins \\
\hline Towns $1,500-5,000$ & 1 & 4 & 3 & 2 & 1 & 0 \\
\hline Towns $5,000-10,000$ & 2 & 5 & 4 & 3 & 2 & 0 \\
\hline Towns $10,000-50,000$ (excl 5 cities) & 3 & 6 & 5 & 4 & 3 & 0 \\
\hline Towns $>50,000$ (i.e., 5 cities) ${ }^{*}$ & 4 & 7 & 6 & 5 & 4 & 0 \\
\hline
\end{tabular}

* Dublin, Cork, Galway, Limerick, Waterford.

transport infrastructure and public transport services to a large rural area pose, the Irish Government developed a transport accessibility index, made up of two components (described in more detail later): (1) proximity to public transport and (2) proximity to service centres (in other words, towns, or large metropolitan centres) [15]. There was a deliberate choice to only include transport related factors in the index and not to include measures of socioeconomic factors which were included in a separate deprivation index.

The key research question addressed here is to what extent proximity to motorways may be contributing to the high incidence of burglaries in rural areas in Ireland and to assess its importance relative to the influence of other variables such as accessibility, deprivation, and the area's population. In addressing the research question presented above, a multinomial logistic regression analysis is conducted using the number of burglaries reported in 2015 in 398 areas in Ireland.

\section{Methods}

The dependent variable, the number of burglaries in an area, was obtained from the crime statistics for 2015 [16]. It should be noted that some potential underreporting of crimes in the database is a possibility, as indicated in a CSO review [17], with a potential error of $10 \%$ noted for burglaries. One of the independent variables, the number of households in an area, was obtained from the 2011 census data [18], the most recent available at the time. Another independent variable, the deprivation index, was obtained from the Central Statistics Office (CSO) databases from the 2011 census [18] and the accessibility index was calculated on the basis of the 2006 census data [15], the most recent available. Proximity to a motorway was measured using Google maps [19]. More detail on how the accessibility and deprivation indices and the proximity to a motorway were obtained is presented below.

2.1. Accessibility Index. The accessibility index was measured by [15] at the level of electoral district (ED) and a score was developed for each. The first part of the score related to access to public transport. For bus stops, a $1 \mathrm{~km}$ zone was created around every bus stop captured and the proportion of the population in the ED that fell within this zone was calculated. The ED received a score on the following basis:

(i) $0 \%$ of ED's population within $1 \mathrm{~km}$ of a bus stop: Score 0 (ii) $1-50 \%$ of ED's population within $1 \mathrm{~km}$ of bus stop: Score 1

(iii) 50 to $99 \%$ of ED's population within $1 \mathrm{~km}$ of a bus stop: Score 2

(iv) $100 \%$ of ED's population within $1 \mathrm{~km}$ of a bus stop: Score 3 [15].

For train stations, a 10-minute off-peak drive time zone was created around every train station captured. A similar scoring system using the same percentages of the population as above was applied; for instance, a score of 0 was given to EDs where $0 \%$ of the population had a drive time to the nearest train station of less than 10 mins and, at the other end of the scale, a score of 3 was given to an ED if $100 \%$ of its population had a drive time to the nearest train station of $<10$ mins. After scoring the EDs for both the bus stop and train station parts of the index above, the ED was given the maximum (not combined) score it received. The maximum an ED could score therefore for proximity to both bus and train services was 3 .

The second part of the accessibility index was the distance to service centre score. Table 1 indicates the scoring system as defined by [15]. Travel times were calculated using average off-peak road speeds. In terms of interpreting the scoring system, if an ED was within 30 mins of a city and also within 10 minutes of a town of between 1,500 and 5,000 residents, a score of 5 was assigned, it being the higher of the two scores allocated. The final stage in creating the accessibility index was to add the two maximum scores from the public transport and service centre analyses, resulting in a range from zero (most inaccessible) to 10 (most accessible).

2.2. Deprivation Index. The deprivation index was calculated by [11] using a number of demographic, social class, and labour market factors from census data to estimate the relative affluence or disadvantage of an area. The deprivation index ranges from -35 (most disadvantaged) to +35 (most affluent) and the frequency distribution for the areas are presented in Figure 1.

2.3. Proximity to Motorway. Motorways are the highest class of road infrastructure and mostly (but not all) operate at speed limits of $120 \mathrm{~km} / \mathrm{hr}$ (74.5 miles per hour) and have at least two lanes in each direction. Roads of lower class can have two lanes in each direction (dual carriageway standard with speed limits of $100 \mathrm{~km} / \mathrm{hr}(62 \mathrm{miles} / \mathrm{hr})$ ) for short stretches but typically they have one lane in each direction and operate 


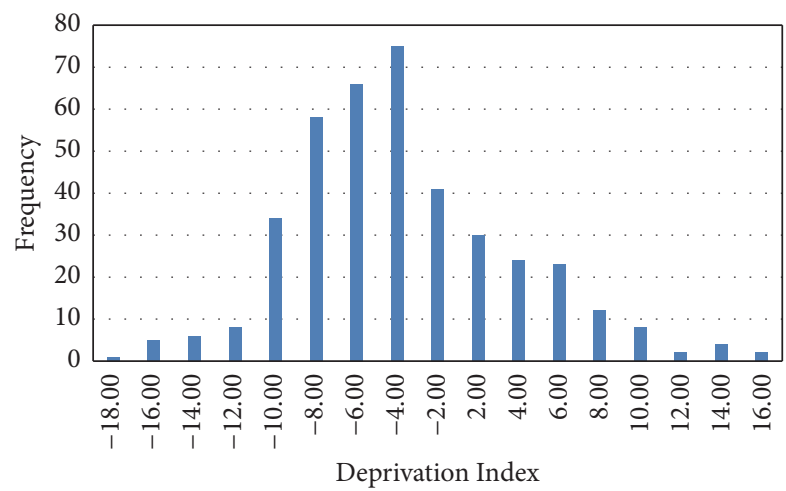

FIGURE 1: Frequency distribution of deprivation index.

at a speed limit of $100 \mathrm{~km} / \mathrm{hr}$. Large parts of the country are not close to the motorway network so it was considered that they would provide adequate controls against which the crime levels in areas close to motorways could be tested.

As the exact location of each burglary was not available, a proxy for the proximity to a motorway was used by measuring the time it took in traffic conditions in minutes from the nearest police station (to which the burglary was reported) to the nearest motorway using Google maps [19]. The results were then binned into the categories used in the analysis presented later.

\section{Results and Discussion}

After testing the correlation level between the number of burglaries from crime statistics for 398 regions within Ireland and deprivation index and finding it to be low at $R^{2}=0.26$, other independent variables were added to the analysis. A multinomial logistic regression was then performed with number of households, accessibility index, deprivation index, and proximity to a motorway (expressway) selected as independent variables. Table 2 includes variable definition and frequencies of the independent variables.

Before including variables in the model, a test for collinearity between them was completed, the results of which are shown in Table 3. It can be seen that each predictor has most of its variance loading on a different dimension indicating no multicollinearity [20]. An overall check on the relationship between the dependent and independent variables is the significance for the final model chi-squared value, after the independent variables have been added, the results of which are shown in Table 4, where significance is evident. The reduction in $-2 \mathrm{LL}$ value for the final model with the independent variables included compared with the model without them can also be seen in Table 4, another indicator that the addition of the independent variables improves the model.

The overall Nagelkerke statistic value was 0.72 representing relatively decent sized effects [20]. It can be seen in Table 4 that all independent variables are significant and therefore add to the model. The larger the chi-square value, the greater the loss of the model fit if that variable was
TABLE 2: Variable definition and frequencies.

\begin{tabular}{|c|c|c|c|}
\hline Variable definition & Value & $N$ & $\%$ \\
\hline \multirow{8}{*}{ Number of burglaries } & $0-10$ & 158 & 39.6 \\
\hline & $11-20$ & 85 & 21.3 \\
\hline & $21-40$ & 61 & 15.3 \\
\hline & $41-60$ & 19 & 4.8 \\
\hline & $61-80$ & 18 & 4.5 \\
\hline & $81-100$ & 8 & 2.0 \\
\hline & $101-200$ & 25 & 6.3 \\
\hline & $201-1000$ & 24 & 6.3 \\
\hline \multirow{8}{*}{ Number of households } & $0-250$ & 61 & 15.3 \\
\hline & $251-500$ & 94 & 23.6 \\
\hline & $501-750$ & 68 & 17.0 \\
\hline & $751-1200$ & 51 & 12.8 \\
\hline & $1201-3000$ & 56 & 14.0 \\
\hline & $3001-5000$ & 27 & 6.8 \\
\hline & $5001-7250$ & 18 & 4.5 \\
\hline & $7251-25000$ & 24 & 6.0 \\
\hline \multirow{26}{*}{ Accessibility index } & 1.00 & 2 & .5 \\
\hline & 3.00 & 4 & 1.0 \\
\hline & 4.00 & 26 & 6.5 \\
\hline & 4.50 & 5 & 1.3 \\
\hline & 5.00 & 46 & 11.5 \\
\hline & 5.20 & 1 & .3 \\
\hline & 5.50 & 13 & 3.3 \\
\hline & 6.00 & 96 & 24.1 \\
\hline & 6.50 & 12 & 3.0 \\
\hline & 6.70 & 1 & .3 \\
\hline & 7.00 & 84 & 21.3 \\
\hline & 7.50 & 2 & .5 \\
\hline & 7.70 & 1 & .3 \\
\hline & 8.00 & 46 & 11.5 \\
\hline & 8.30 & 1 & .3 \\
\hline & 8.40 & 1 & .3 \\
\hline & 8.50 & 4 & 1.0 \\
\hline & 8.60 & 2 & .5 \\
\hline & 8.70 & 3 & .8 \\
\hline & 8.80 & 2 & .5 \\
\hline & 9.00 & 32 & 8.0 \\
\hline & 9.10 & 1 & .3 \\
\hline & 9.30 & 1 & .3 \\
\hline & 9.60 & 1 & .3 \\
\hline & 9.70 & 1 & .3 \\
\hline & 10.00 & 10 & 2.5 \\
\hline & -18.00 & 1 & .3 \\
\hline & -16.00 & 5 & 1.3 \\
\hline & -14.00 & 6 & 1.5 \\
\hline & -12.00 & 8 & 2.0 \\
\hline & -10.00 & 34 & 8.5 \\
\hline & -8.00 & 58 & 14.5 \\
\hline & -6.00 & 66 & 16.5 \\
\hline & -4.00 & 74 & 18.8 \\
\hline Deprivation index & -2.00 & 41 & 10.3 \\
\hline
\end{tabular}


TABLE 2: Continued.

\begin{tabular}{|c|c|c|c|}
\hline Variable definition & Value & $N$ & $\%$ \\
\hline & 2.00 & 30 & 7.5 \\
\hline & 4.00 & 24 & 6.0 \\
\hline & 6.00 & 23 & 5.8 \\
\hline & 8.00 & 12 & 3.0 \\
\hline & 10.00 & 8 & 2.0 \\
\hline & 12.00 & 2 & .5 \\
\hline & 14.00 & 4 & 1.0 \\
\hline & 16.00 & 2 & .5 \\
\hline \multirow{15}{*}{ Proximity to motorway (mins) } & 4.00 & 12 & 3.0 \\
\hline & 5.00 & 25 & 6.3 \\
\hline & 8.00 & 42 & 10.5 \\
\hline & 9.00 & 34 & 8.5 \\
\hline & 12.00 & 12 & 3.0 \\
\hline & 13.00 & 76 & 19.3 \\
\hline & 15.00 & 20 & 5.0 \\
\hline & 21.00 & 32 & 8.0 \\
\hline & 28.00 & 15 & 3.8 \\
\hline & 31.00 & 27 & 6.8 \\
\hline & 44.00 & 12 & 3.0 \\
\hline & 47.00 & 20 & 5.0 \\
\hline & 85.00 & 21 & 5.3 \\
\hline & 92.00 & 32 & 8.0 \\
\hline & 94.00 & 18 & 4.5 \\
\hline
\end{tabular}

dropped. In this case, dropping number of households would result in the greatest loss of model fit, followed by accessibility index, proximity to motorway, and deprivation index, in that order. What is of interest here is the relatively low influence deprivation index is having on the model and this would not appear to support findings of other work [1]. Of further interest is the somewhat higher influence in the model of the accessibility index. Interpretation of this finding is complicated in that it combines proximity to public transport stations as well as an indication of how close the area is to a town or urban centre. The results support the results of others $[4,5]$ in suggesting that higher crime levels are evident in higher density or urban areas.

Classification accuracy compares the predicted group membership based on the logistic model with the actual. The benchmark is that the model is considered useful if it shows a $25 \%$ improvement over the rate of accuracy achievable by chance alone. The proportional by chance accuracy was computed by calculating the proportion of cases for each group based on the number of cases in each group for the dependent variable in Table 2 and then squaring and summing the proportion of cases in each group, the result of which was calculated to be 0.27 . The proportional by chance accuracy criteria therefore $=1.25 * 0.27=34 \%$. The classification accuracy rate from the model was calculated to be $54.3 \%$ from Table 5 indicating that the model can be characterized as useful.

The model parameter estimates are presented in Table 6. The reference category refers to areas with more than 200 burglaries recorded and against which all other categories are referenced. Working down through each variable and examining the $B$ values, we first look at the deprivation index. The $B$ values are significant for the categories of $21-40,41-60$, and 101-200 burglaries which suggests that deprivation index is significant in distinguishing between geographical areas in those categories and areas in the reference category of $>200$ burglaries. The value of $\exp (B)$ of 0.847 for deprivation index in the 41-60-burglary category suggests that for every one unit increase in deprivation index the odds of an area with 41-60 reported burglaries decreased by $19 \%$ (0.814 $1=-0.186)$. The $\exp (B)$ values for the 21-40- and 101-200burglary categories were similar at 0.847 and 0.895 suggesting similar relationships, all measured against the reference category, and when all other variables are controlled.

In examining the parameter estimates for the accessibility index, it can be noted first of all that this variable is significant in distinguishing the first three categories from the reference category but not for the others. Looking at the $\exp (B)$ values for the 0-10-burglary category, increasing the accessibility index by one unit would decrease the probability of an area being in the 0-10-burglary reported burglary category by $90 \%$. Decreases in probability are also evident for the second and third categories, by $84 \%$ for the 11-20-burglary category and by $80 \%$ for the $21-40$-reported-burglary category.

The number of households in an area is significant for almost all categories to some level except for one and the $\exp (B)$ values are all similar at $\sim 0.999$ or 1 meaning that for a unit increase in the number of households there is little change in the odds of an area being in those categories relative to the reference category. The last variable examined was the proximity of an area to a motorway. While the addition of this variable to the model was indicated as significant in Table 4, that is, it improved the model by its inclusion, it was not significant in distinguishing the categories from the reference category. To further demonstrate that proximity of an area to a motorway does not appear to influence the number of burglaries in that area, analysis of variance tests was completed indicating there was a significant difference between the proximity to motorway groups, $F(6,391)=45$, $P=0.001$, but Games Howell post hoc tests revealed the differences were not between the lower and higher proximity distance groups as can be seen in Figure 2 where the means and confidence intervals (CI) are plotted. Overlap between the $\mathrm{CI}$ for the $20,30,90$, and $100 \mathrm{~km}$ groups in particular suggests similarity in numbers of burglaries in these groups. Overlap is also evident for the 10 and $50 \mathrm{~km}$ proximity to motorway groupings.

The findings in relation to the influence of the number of households in an area and accessibility index tend to concur with the research of others $[4,5]$ who have suggested crime is higher in urban areas and in neighborhoods with high population density. Other research $[7,21-23]$ found a strong association between inequality and violent and property crime rates and this is somewhat aligned with the findings here in relation to the influence of deprivation where it was a useful indicator in some cases.

Offenders are known to commute a greater distance to commit a crime in rural areas [24], and in a rural context, the danger posed by outsiders has traditionally been seen as a 
TABLE 3: Collinearity diagnostics.

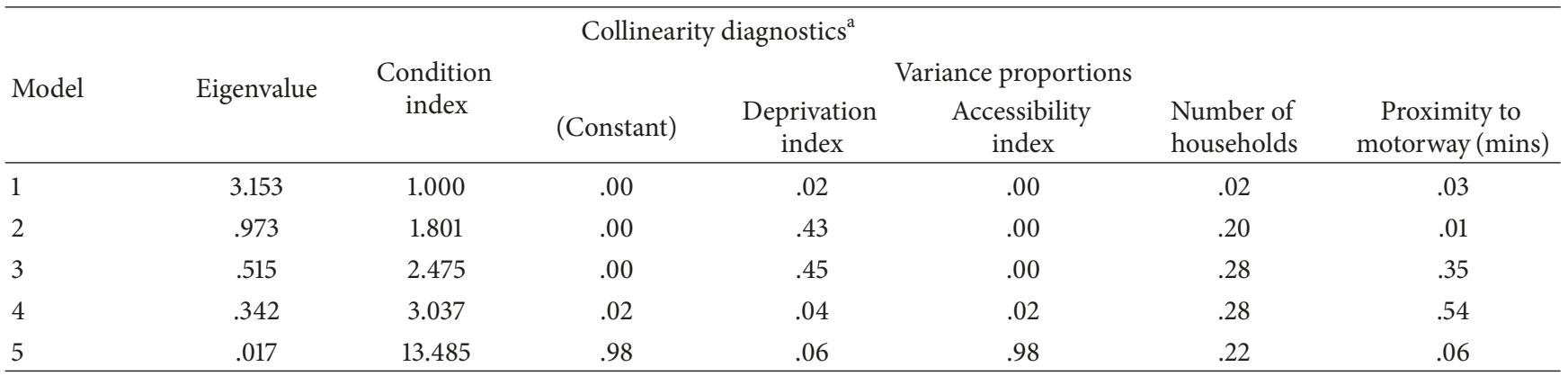

a. Dependent variable: number of burglaries.

TABLE 4: Model fitting and statistical significance of independent variables.

(a) Model fitting information

\begin{tabular}{lccc}
\hline Model & Model fitting criteria & & \multicolumn{2}{c}{ Likelihood ratio tests } \\
& $-2 \log$ likelihood & Chi-square & Sf \\
\hline Intercept only & 1345.955 & 475.139 & 28 \\
Final & 870.816 & & .000 \\
$N$ & 398 & & \\
Nagelkerke & 0.72 & & \\
\hline
\end{tabular}

(b) Likelihood ratio tests

\begin{tabular}{lcccc}
\hline \multirow{2}{*}{ Effect } & \multicolumn{2}{c}{ Model fitting criteria } & \multicolumn{2}{c}{ Likelihood ratio tests } \\
& $-2 \log$ likelihood of reduced model & Chi-square & df & Sig. \\
\hline Intercept & 979.601 & 108.785 & 7 & .000 \\
Deprivation index & 892.174 & 21.358 & 7 & .003 \\
Accessibility index & 913.287 & 42.471 & 7 & .000 \\
Number of households & 1051.345 & 180.530 & .000 \\
Proximity to motorway (mins) & 892.953 & 22.137 & 7 & 7 \\
\hline
\end{tabular}

TABLE 5: Classification table.

\begin{tabular}{|c|c|c|c|c|c|c|c|c|c|}
\hline \multirow{3}{*}{ Observed } & \multicolumn{9}{|c|}{ Classification } \\
\hline & & & & & & edicted & & & \\
\hline & $0-10$ & $11-20$ & $21-40$ & $41-60$ & $61-80$ & $81-100$ & $101-200$ & $201-1000$ & Percent correct (\%) \\
\hline 1.00 & 137 & 14 & 7 & 0 & 0 & 0 & 0 & 0 & $86.7 \%$ \\
\hline 2.00 & 53 & 27 & 4 & 0 & 0 & 0 & 1 & 0 & $31.8 \%$ \\
\hline 3.00 & 17 & 19 & 21 & 0 & 0 & 0 & 4 & 0 & $34.4 \%$ \\
\hline 4.00 & 2 & 2 & 11 & 1 & 1 & 0 & 2 & 0 & $5.3 \%$ \\
\hline 5.00 & 0 & 0 & 8 & 2 & 3 & 0 & 4 & 1 & $16.7 \%$ \\
\hline 6.00 & 0 & 0 & 3 & 0 & 1 & 0 & 2 & 2 & $0.0 \%$ \\
\hline 7.00 & 1 & 0 & 4 & 1 & 2 & 0 & 11 & 6 & $44.0 \%$ \\
\hline 8.00 & 0 & 0 & 0 & 0 & 2 & 0 & 6 & 16 & $66.7 \%$ \\
\hline Overall\% & $52.8 \%$ & $15.6 \%$ & $14.6 \%$ & $1.0 \%$ & $2.3 \%$ & $0.0 \%$ & $7.5 \%$ & $6.3 \%$ & $54.3 \%$ \\
\hline
\end{tabular}

threat to rural communities $[25,26]$. In the work presented here, proximity to fast road infrastructure was found to have limited influence on the number of burglaries in rural areas compared with the other variables tested. However, research in Australia found that for farm crime properties that are easily accessible by roads may be targeted [27]. Others have noted the common phenomenon of criminals from nearby cities travelling to a rural area to commit a crime and returning home [28].

3.1. Strengths and Limitations of the Research. The main strength of the research was the strong predictive performance of the model with a Nagelkerke $R^{2}$ value of 0.72 indicating that the set of independent variables used are 
TABLE 6: Multinomial logistic regression model parameter estimate results.

\begin{tabular}{|c|c|c|c|c|c|c|c|c|}
\hline \multirow{3}{*}{ Number of reported burglaries ${ }^{a}$} & \multicolumn{8}{|c|}{ Parameter estimates } \\
\hline & \multirow{2}{*}{$B$} & \multirow{2}{*}{ Std. error } & \multirow{2}{*}{ Wald } & \multirow{2}{*}{$\mathrm{df}$} & \multirow{2}{*}{ Sig. } & \multirow{2}{*}{$\exp (B)$} & \multicolumn{2}{|c|}{$95 \%$ confidence interval for $\exp (B)$} \\
\hline & & & & & & & Lower bound & Upper bound \\
\hline \multicolumn{9}{|l|}{$0-10$} \\
\hline Intercept & 26.325 & 5.665 & 21.596 & 1 & .000 & & & \\
\hline Deprivation index & -.042 & .074 & .328 & 1 & .567 & .958 & .829 & 1.108 \\
\hline Accessibility index & -2.301 & .626 & 13.527 & 1 & .000 & .100 & .029 & .341 \\
\hline Number of households & -.004 & .000 & 70.315 & 1 & .000 & .996 & .995 & .997 \\
\hline Proximity to motorway (mins) & .024 & .018 & 1.672 & 1 & .196 & 1.024 & .988 & 1.061 \\
\hline \multicolumn{9}{|l|}{$11-20$} \\
\hline Intercept & 22.388 & 5.645 & 15.730 & 1 & .000 & & & \\
\hline Deprivation index & -.122 & .073 & 2.805 & 1 & .094 & .885 & .768 & 1.021 \\
\hline Accessibility index & -1.836 & .620 & 8.762 & 1 & .003 & .159 & .047 & .538 \\
\hline Number of households & -.003 & .000 & 52.478 & 1 & .000 & .997 & .997 & .998 \\
\hline Proximity to motorway (mins) & .010 & .018 & .288 & 1 & .591 & 1.010 & .974 & 1.046 \\
\hline \multicolumn{9}{|l|}{$21-40$} \\
\hline Intercept & 19.450 & 5.597 & 12.077 & 1 & .001 & & & \\
\hline Deprivation index & -.166 & .069 & 5.773 & 1 & .016 & .847 & .740 & .970 \\
\hline Accessibility index & -1.617 & .613 & 6.963 & 1 & .008 & .198 & .060 & .660 \\
\hline Number of households & -.001 & .000 & 31.079 & 1 & .000 & .999 & .998 & .999 \\
\hline Proximity to motorway (mins) & .002 & .018 & .017 & 1 & .897 & 1.002 & .968 & 1.038 \\
\hline \multicolumn{9}{|l|}{$41-60$} \\
\hline Intercept & 15.748 & 5.681 & 7.686 & 1 & .006 & & & \\
\hline Deprivation index & -.206 & .075 & 7.607 & 1 & .006 & .814 & .703 & .942 \\
\hline Accessibility index & -1.327 & .629 & 4.449 & 1 & .035 & .265 & .077 & .910 \\
\hline Number of households & -.001 & .000 & 15.493 & 1 & .000 & .999 & .999 & 1.000 \\
\hline Proximity to motorway (mins) & -.019 & .021 & .815 & 1 & .367 & .981 & .940 & 1.023 \\
\hline \multicolumn{9}{|l|}{$61-80$} \\
\hline Intercept & 11.668 & 5.632 & 4.293 & 1 & .038 & & & \\
\hline Deprivation index & -.118 & .066 & 3.204 & 1 & .073 & .888 & .780 & 1.011 \\
\hline Accessibility index & -.880 & .618 & 2.031 & 1 & .154 & .415 & .124 & 1.391 \\
\hline Number of households & -.001 & .000 & 14.526 & 1 & .000 & .999 & .999 & 1.000 \\
\hline Proximity to motorway (mins) & -.008 & .018 & .214 & 1 & .643 & .992 & .957 & 1.028 \\
\hline \multicolumn{9}{|l|}{$81-100$} \\
\hline Intercept & 13.015 & 6.073 & 4.592 & 1 & .032 & & & \\
\hline Deprivation index & -.061 & .076 & .644 & 1 & .422 & .941 & .811 & 1.092 \\
\hline Accessibility index & -1.275 & .690 & 3.410 & 1 & .065 & .279 & .072 & 1.081 \\
\hline Number of households & .000 & .000 & 4.131 & 1 & .042 & 1.000 & .999 & 1.000 \\
\hline Proximity to motorway (mins) & -.017 & .024 & .460 & 1 & .497 & .984 & .938 & 1.032 \\
\hline \multicolumn{9}{|l|}{$101-200$} \\
\hline Intercept & 8.953 & 5.490 & 2.659 & 1 & .103 & & & \\
\hline Deprivation index & -.111 & .056 & 3.975 & 1 & .046 & .895 & .802 & .998 \\
\hline Accessibility index & -.714 & .600 & 1.415 & 1 & .234 & .490 & .151 & 1.587 \\
\hline Number of households & .000 & .000 & 8.168 & 1 & .004 & 1.000 & .999 & 1.000 \\
\hline Proximity to motorway (mins) & .005 & .014 & .110 & 1 & .741 & 1.005 & .977 & 1.033 \\
\hline
\end{tabular}

a. The reference category is areas with $>200$ burglaries.

useful in predicting the number of burglaries in an area. Most of this predictive power is driven by the population of the area and would be expected, but the work also highlights the importance of accessibility and deprivation, the latter having less influence than suggested by other research [1].
Accessibility is grounded in proximity to public transport and/or to a town or city and, as the second most influential variable in the model, suggests that burglary levels are higher when accessibility values are higher, another intuitive result. Although proximity to motorways is indicated as a 


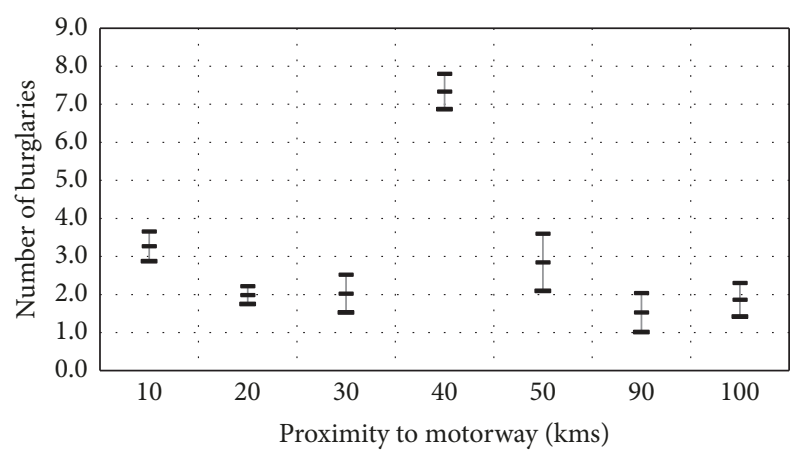

FIGURE 2: Means and confidence intervals of proximity to motorway groups.

statistically significant variable in the model, it is not useful in distinguishing areas by burglary rate which means it is not as useful a predictor.

A limitation of the work is that the data for all variables were not available for the same year. The accessibility index was derived by previous research for 2006 but was not repeated for later census data [15]. However, as it focuses on the proximity of a household to a bus stop and/or to a town or urban area, changes from year to year would be marginal and most influenced by a change in a bus route which in rural areas is subject to limited change. In terms of the methodological implications, an assessment was made of the potential impact of using the 2006 accessibility index with data from two other time points. The conclusion of the assessment was that while this is a limitation of the analysis, the potential error is likely to be small given the typically fixed nature of rural public transport routes year on year. Having said that, there is potential for some error but it is difficult to quantify. At the time the research was conducted, the 2011 census was the most recent and was used for obtaining the number of households and deprivation index. In terms of methodological implications, an assessment was made of the potential impact of using data from 2011 and combining it with data from two other time points. The alternative was to use census data from an earlier census, closer in time to 2006. On balance, and again due to the limited change in accessibility expected, year on year, it was decided that using the 2011 census data would be useful in capturing more recent household and deprivation index data. It is unlikely that there was a significant change in the number of households and deprivation between 2011 and 2015 as the country was in deep recession during those years with limited house building and an unchanging economic climate over that period, but some change cannot be discounted.

In relation to the choice of 2015 for the crime statistics data, this was necessary because data was not available in sufficiently accurate form for the year 2011 [17]. Improvements were made to the data collection and recording process by the police authority after 2011 following recommendations by the CSO [17] with a further review of the 2015 data demonstrating improvements, although a potential $10 \%$ underreporting in relation to burglaries is still likely in the 2015 data used here [17]. To assess the potential impact of the error, the model was rerun, after an average correction to allow for the underreporting was applied across the data. The observed predictive power for all independent variables improved marginally except for the accessibility index along with a slightly improved Nagelkerke $R^{2}$ value of 0.76 . Again, the implications of using a different year for the crime data were assessed and the advantages and disadvantages were considered. Having assessed the information provided in the review by the CSO [17] of both the 2011 and 2015 datasets, it was considered prudent to use the 2015 dataset [17].

Another weakness was the reporting of crime statistics by police station at which they are reported rather than by the precise location of the crime. This was less than ideal and an assessment was made to consider the methodological implications and resulting limitations to the work. Individuals report crimes to the police station based in their area. The 398 police stations outside of Dublin county, and the focus of the analysis here, are located across the country, the geographical area of which is $70,273 \mathrm{~km}^{2}$. At county level, some examples demonstrate the extent of the variation. Galway county has an area of $6,149 \mathrm{~km}^{2}$ and 46 police stations cover that area meaning each covers an area of $133 \mathrm{~km}^{2}$ on average giving an average radius from the police station to the edge of the area it covers of $6.5 \mathrm{~km}$, assuming the police station is based at the centre of a circular area. Another large county has 27 police stations to cover $4,861 \mathrm{~km}^{2}$ meaning each covers $180 \mathrm{~km}^{2}$ with an average radius of $7.6 \mathrm{~km}$, assuming a circular area of coverage (and assuming the road runs on a radial of the circle). An extrapolation of this to estimate the implications on the travel time to the nearest motorway would be perhaps overly simplistic and fraught with error but, for instance, a $10 \mathrm{~km}$ difference assuming a worst case scenario of the criminals travelling at the national speed limit of $80 \mathrm{~km} / \mathrm{hr}$ would result in an error of 7.5 minutes. If they were using excessive speed, as might be expected when departing the scene of a crime, then this would be lower (at $100 \mathrm{~km} / \mathrm{hr}$ it would be $6 \mathrm{mins}$, at $120 \mathrm{~km} / \mathrm{hr}$ it would be $5 \mathrm{mins}$ ). It is difficult to assess how this error affects the model outcome but it is important to note there is an error associated with this variable.

\section{Conclusions}

The paper examines the influence of a number of area descriptive factors on crime rates, measured for the purposes of the work presented here, as number of burglaries reported in 2015. In particular, it examined the number of households in an area, accessibility index, deprivation index, and the proximity to fast road infrastructure. The logistic regression modelling exercise found that the number of households in an area had most influence on crime levels, followed by the accessibility index, proximity to motorway, and deprivation index in that order. Interesting results include the marginally higher relative importance of accessibility index compared with deprivation index suggesting that greater accessibility, influenced in part by proximity to a town or urban centre, has somewhat more influence on crime rates than the deprivation level of the area. While the proximity of an area to a motorway 
is shown in the model to be significant and improved the model marginally, its influence is not one that distinguishes areas of high and low distance from motorways in terms of the number of burglaries. This seems to refute the hypothesis that rural crime levels in areas close to fast road infrastructure were higher because of the efficient escape routes it provides for city based gangs.

\section{Conflicts of Interest}

The author declares that there are no conflicts of interest.

\section{References}

[1] J. Savolainen, R. Paananen, M. Merikukka, M. Aaltonen, and M. Gissler, "Material deprivation or minimal education? Social class and crime in an egalitarian welfare state," Advances in Life Course Research, vol. 18, no. 3, pp. 175-184, 2013.

[2] J. G. Bernburg, T. Thorlindsson, and I. D. Sigfusdottir, "Relative deprivation and adolescent outcomes in Iceland: A multilevel test," Social Forces, vol. 87, no. 3, pp. 1223-1250, 2009.

[3] R. Hudson, "Thinking through the relationships between legal and illegal activities and economies: spaces, flows and pathways," Journal of Economic Geography, vol. 14, no. 4, pp. 775795, 2014.

[4] S. L. Myers Jr., "Crime in urban areas: New evidence and results," Journal of Urban Economics, vol. 11, no. 2, pp. 148-158, 1982.

[5] I. Hoch, "Factors in urban crime," Journal of Urban Economics, vol. 1, no. 2, pp. 184-229, 1974.

[6] G. Drawve and J. D. Barnum, "Place-based risk factors for aggravated assault across police divisions in Little Rock, Arkansas," Journal of Crime and Justice, vol. 41, no. 2, pp. 173192, 2018.

[7] A. W. Chamberlain and J. R. Hipp, "It's all relative: Concentrated disadvantage within and across neighborhoods and communities, and the consequences for neighborhood crime," Journal of Criminal Justice, vol. 43, no. 6, pp. 431-443, 2015.

[8] P. Cabrera-Barona, C. Wei, and M. Hagenlocher, "Multiscale evaluation of an urban deprivation index: Implications for quality of life and healthcare accessibility planning," Applied Geography, vol. 70, pp. 1-10, 2016.

[9] T. D. Stucky, S. B. Payton, and J. R. Ottensmann, "Intra- and inter-neighborhood income inequality and crime," Journal of Crime and Justice, vol. 39, no. 3, pp. 345-362, 2016.

[10] T. Haase and J. Pratschke, Deprivation and its Spatial Articulation in the Republic of Ireland, 2005, http://trutzhaase.eu/ wp/wp-content/uploads/R-2005-Deprivation-and-its-SpatialArticulation.pdf.

[11] T. Haase, J. Pratschke, and J. Gleeson, "All-island deprivation index: towards the development of consistent deprivation measures for the island of Ireland," Borderlands: The Journal of Spatial Planning in Ireland, pp. 21-37, 2012.

[12] V. Spicer and J. Song, "The impact of transit growth on the perception of crime," Journal of Environmental Psychology, vol. 54, pp. 151-159, 2017.

[13] P. Cozens, R. Neale, J. Whitaker, and D. Hillier, "Managing crime and the fear of crime at railway stations-a case study in South Wales (UK)," International Journal of Transport Management, vol. 1, no. 3, pp. 121-132, 2003.
[14] O. T. McCarthy, B. Caulfield, and M. O'Mahony, "How transport users perceive personal safety apps," Transportation Research Part F: Traffic Psychology and Behaviour, vol. 43, pp. 166-182, 2016.

[15] Gamma and T. Haase, "Towards the development of a transport accessibility index. An analysis of geographical remoteness to support the Rural Transport Programme in the Republic of Ireland," http://trutzhaase.eu/publications/towards-thedevelopment-of-a-transport-accessibility-index/.

[16] CSO Crime Statistics, 2015, http://www.cso.ie/en/statistics/ crimeandjustice/.

[17] CSO, "Review of quality of crime statistics 2016," http://www .cso.ie/en/media/csoie/releasespublications/documents/crimejustice/2016/reviewofcrime.pdf.

[18] CSO, Census 2011 Place of Work-Census of Anonymised Records (POWSCAR), Central Statistics Office, Cork, Ireland, 2012.

[19] Google maps https://maps.google.com/, 2017.

[20] A. Field, Discovering Statistics Using IBM SPSS Statistics, Sage Publishing, 4th edition, 2012.

[21] P. Buonanno and J. F. Vargas, "Inequality, crime, and the long run legacy of slavery," Journal of Economic Behavior \& Organization, 2017.

[22] T. C. Pratt and F. T. Cullen, "Assessing macro-level predictors and theories of crime: a meta-analysis," Crime and Justice, vol. 32, pp. 373-450, 2005.

[23] R. J. Sampson, J. D. Morenoff, and T. Gannon-Rowley, "Assessing "neighborhood effects": social processes and new directions in research," Annual Review of Sociology, vol. 28, pp. 443-478, 2002.

[24] P. Wiles and A. Costello, The "Road to Nowhere": The Evidence for Travelling Criminals, HO Research Study no. 207, Home Office, London, UK, 2000.

[25] D. Gilling, "Governing crime in rural UK: risk and representation," in Constable Countryside: Policing, Rurality and Governance, R. I. Mawby and R. Yardley, Eds., pp. 69-79, Ashgate, Aldershot, UK, 2011.

[26] K. Halfacree, "Still 'out of place in the country'? Travellers and the post productivist rural," in Constable Countryside: Policing, Rurality and Governance, R. I. Mawby and R. Yardley, Eds., pp. 123-135, Ashgate, Aldershot, UK, 2011.

[27] E. Barclay and J. F. Donnermeyer, "Crime and security on agricultural operations," Security Journal, vol. 24, no. 1, pp. 1-18, 2011.

[28] R. I. Mawby, "Exploring the relationship between crime and place in the countryside," Journal of Rural Studies, vol. 39, pp. 262-270, 2015. 


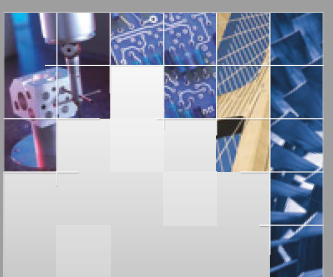

\section{Enfincering}
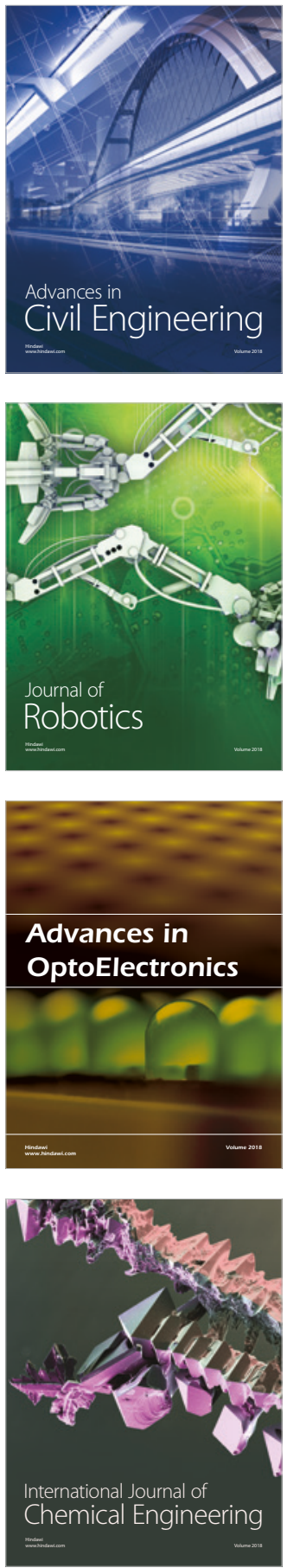

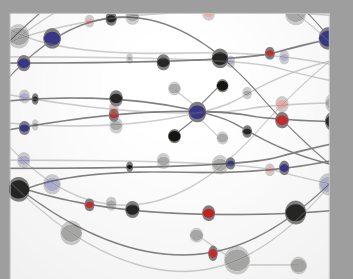

\section{Rotating \\ Machinery}

The Scientific World Journal

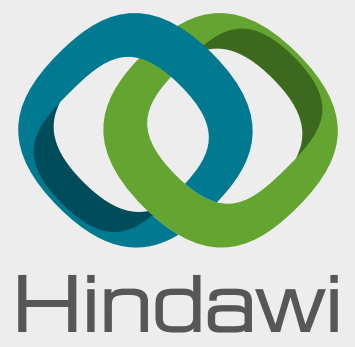

Submit your manuscripts at

www.hindawi.com
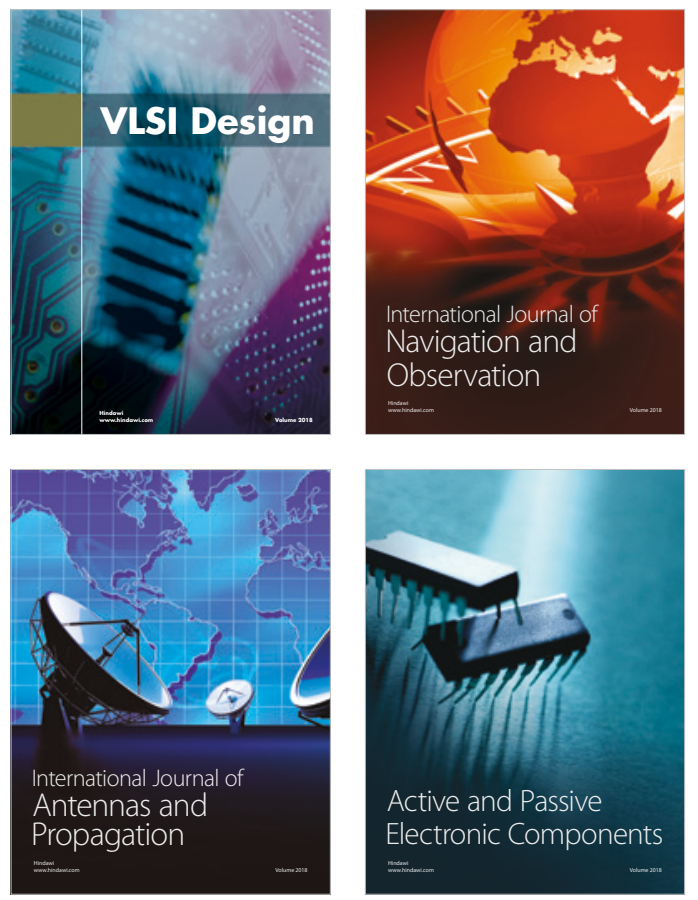
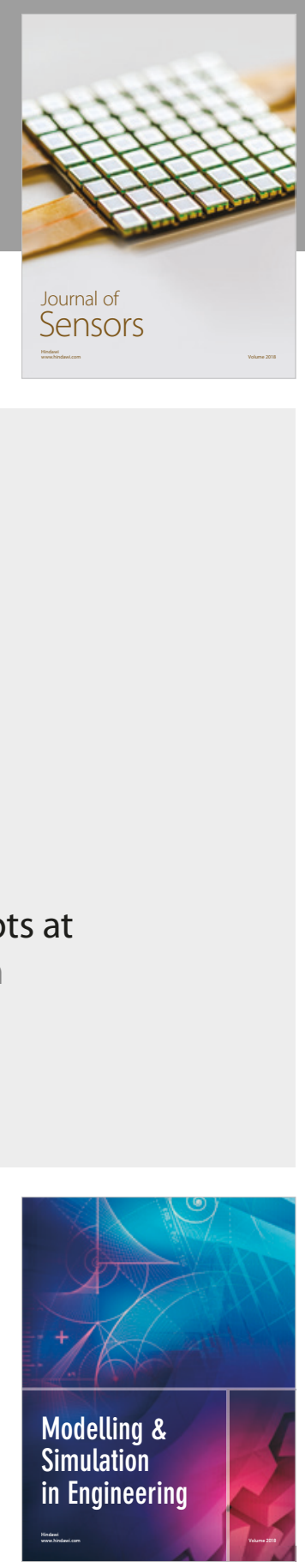

\section{Advances \\ Multimedia}
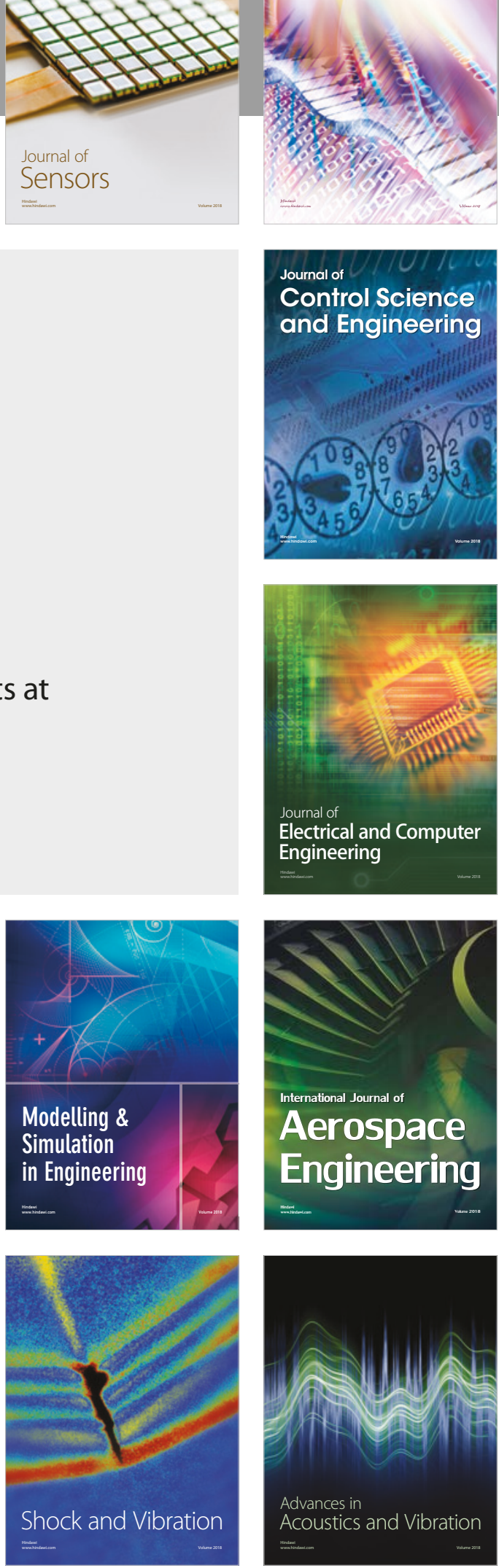